\title{
Prevalence and risk factors of helminths and intestinal protozoa infections among children from primary schools in western Tajikistan
}

\author{
Barbara Matthys ${ }^{1,2^{*}}$, Mohion Bobieva ${ }^{3}$, Gulzira Karimova ${ }^{4}$, Zulfira Mengliboeva ${ }^{4}$, Vreni Jean-Richard ${ }^{2,4,5}$, \\ Malika Hoimnazarova ${ }^{3}$, Matluba Kurbonova ${ }^{3}$, Laurent K Lohourignon ${ }^{6}$, Jürg Utzinger ${ }^{2,5}$ and Kaspar Wyss ${ }^{1,2}$
}

\begin{abstract}
Background: Intestinal parasitic infections represent a public health problem in Tajikistan, but epidemiological evidence is scarce. The present study aimed at assessing the extent of helminths and intestinal protozoa infections among children of 10 schools in four districts of Tajikistan, and to make recommendations for control.

Methods: A cross-sectional survey was carried out in early 2009. All children attending grades 2 and 3 (age: 7-11 years) from 10 randomly selected schools were invited to provide a stool sample and interviewed about sanitary situation and hygiene behaviour. A questionnaire pertaining to demographic and socioeconomic characteristics was addressed to the heads of households. On the spot, stool samples were subjected to duplicate Kato-Katz thick smear examination for helminth diagnosis. Additionally, 1-2 $\mathrm{g}$ of stool was fixed in sodium acetate-acetic acidformalin, transferred to a specialised laboratory in Europe and examined for helminths and intestinal protozoa. The composite results from both methods served as diagnostic 'gold' standard.
\end{abstract}

Results: Out of 623 registered children, 602 participated in our survey. The overall prevalence of infection with helminths and pathogenic intestinal protozoa was $32.0 \%$ and $47.1 \%$, respectively. There was pronounced spatial heterogeneity. The most common helminth species was Hymenolepis nana (25.8\%), whereas the prevalences of Ascaris lumbricoides, hookworm and Enterobius vermicularis were below 5\%. The prevalence of pathogenic intestinal protozoa, namely Giardia intestinalis and Entamoeba histolytica/E. dispar was 26.4\% and 25.9\%, respectively. Almost half of the households draw drinking water from unimproved sources, such as irrigation canals, rivers and unprotected wells. Sanitary facilities were pit latrines, mostly private, and a few shared with neighbours. The use of public tap/standpipe as a source of drinking water emerged as a protective factor for $G$. intestinalis infection. Protected spring water reduced the risk of infection with E. histolytica/E. dispar and H. nana.

Conclusions: Our data obtained from the ecological 'lowland' areas in Tajikistan call for school-based deworming (recommended drugs: albendazole and metronidazole), combined with hygiene promotion and improved sanitation. Further investigations are needed to determine whether $H$. nana represents a public health problem.

\section{Background}

Infections with helminths (e.g. Ascaris lumbricoides, hookworm, Hymenolepis nana and Trichuris trichiura) and intestinal protozoa (e.g. the pathogenic Entamoeba histolytica and Giardia intestinalis) are closely linked with conditions of poverty, unsafe water, sanitation and

\footnotetext{
* Correspondence: barbara.matthys@unibas.ch

'Swiss Centre for International Health, Swiss Tropical and Public Health Institute, P.O. Box, CH-4002 Basel, Switzerland

Full list of author information is available at the end of the article
}

hygiene [1]. More than 2 billion people might be infected with helminths, mainly in the developing world [2]. At highest risk of morbidity are pre-school and school-aged children and pregnant women [3]. Negative effects of helminth infections include diminished physical fitness and growth retardation, and delayed intellectual development and cognition [2,3]. Vitamin A deficiency, malabsorption of vitamin $\mathrm{B}_{12}$ and fat and nutritional deficiencies in children might be associated with G. intestinalis, which may lead to serious organ 
damage [4]. Morbidity due to E. histolytica includes diarrhoea and dysentery in children and liver abscess in severe cases [5].

It is widely acknowledged that helminthiasis and intestinal protozoa infections are of considerable public health importance in Tajikistan and elsewhere in Central Asia [6,7], but the geographical distribution and regional burden remain to be determined. Previous research has mainly focussed on parasitic diseases of livestock and most of the available literature is in Russian. Recently, the World Health Organization (WHO) presented a simple methodology to assess the prevalence of helminths, stratified by ecozones, for settings where information is scarce [8]. Once high-risk areas are identified (e.g. $>20 \%$ of school-aged children infected with soiltransmitted helminths), WHO recommends deworming of all school-aged children at least once every year [9]. Whenever resources allow, deworming should be complemented with improved access to safe drinking water and sanitation, health education and hygiene behaviour change, coupled with regular monitoring and surveillance. Several countries have launched their helminthiasis control programmes and made progress towards achieving deworming coverage rates of $75 \%$ of schoolaged children [10].

The Swiss Health Reform and Family Medicine Support Project (Project Sino in short) in Tajikistan contributes to the national health sector reform programme. The project aims to improve the population's health status and access to health services, particularly for poor groups. Among other issues, the project developed an accessible and sustainable family medicine model that is affordable by local communities as shown in pilot districts. The project initiates further evidence-based activities and encourages operational research at the interface of family medicine services and communities with an emphasis on reducing the burden of diseases that are of public health importance [11-16]. The aim of the present study was to assess the prevalence of helminths and intestinal protozoa infections among schoolaged children in four districts of Project Sino, and to make recommendations for control.

\section{Materials and methods}

\section{Study area and context}

Tajikistan is a mountainous land-locked country in Central Asia with approximately 7 million inhabitants, most of whom live in rural areas (73.7\% in 2009) [17,18]. In 2010, the per capita gross development product (GDP) was US\$ 2, 000, and hence Tajikistan ranked at position 190 out of 228 countries included in the list of the CIA world factbook [19]. Even though the national economy has grown considerably in the past several years, twothirds of the population still live on less than US\$ 2.15 per day. Agriculture remains the primary sector of the national economy, contributing $24 \%$ of the national GDP and $66 \%$ of employment. Remittances are a vital source of income for many Tajik households, facilitated through working in the construction sector in Russia. Labour migrants are primarily young men from rural areas [20].

The regional climate is continental, close to Mediterranean with dominant spring-winter precipitation, hot and dry summers and cold winters [21]. Water is becoming increasingly scarce due to rapid shrinkage of glaciers, conflicts with neighbouring downstream countries on water provision used for irrigation purposes (for cotton and to a lesser extent rice cultivation), and deterioration of irrigation and drainage systems [20].

Our study was carried out in four districts of Project Sino located in the western part of Tajikistan in early 2009 (Figure 1). Prior to our survey, relevant literature considering the local context of Tajikistan (e.g. peerreviewed articles obtained from searching electronic databases such as PubMed and ISI Web of Knowledge) and reports and national statistics from WHOLIS and the WHO regional office in Europe were reviewed.

\section{Selection of study population}

Schoolchildren attending grades 2 and 3 (age: 7-11 years) were chosen according to WHO recommendations [22]. Schools are a convenient platform to conduct surveys and schoolchildren are at high risk of infections with helminths and other intestinal parasites. Selection of a relatively narrow age range results in smaller confidence intervals around point prevalence estimates. School enrolment rates are high in Tajikistan, i.e. 97\% primary net school enrolment in 2005-2009 [23]. We adhered to a rapid appraisal methodology proposed by WHO, suggesting a minimum of 50 schoolchildren to be examined per school $[8,9]$.

\section{Study design and selection of schools}

In a first step, the heads of educational departments from all four districts were asked by a Project Sino representative for community outreach activities in January 2009 to prepare a list of all primary schools in their respective district, including the number of children attending grades 2 and 3. A total number of 300 primary schools were listed in these districts. In 143 of these schools, less than 50 children attended grades 2 and 3, and hence these were excluded. Another 10 schools from one district were excluded because of recent deworming activities implemented by a non-governmental organization (NGO). From the remaining 147 schools, 10 were selected by means of a simple random sampling procedure. In each school, 60-70 children were selected (allowing for drop-outs to gather data from at 


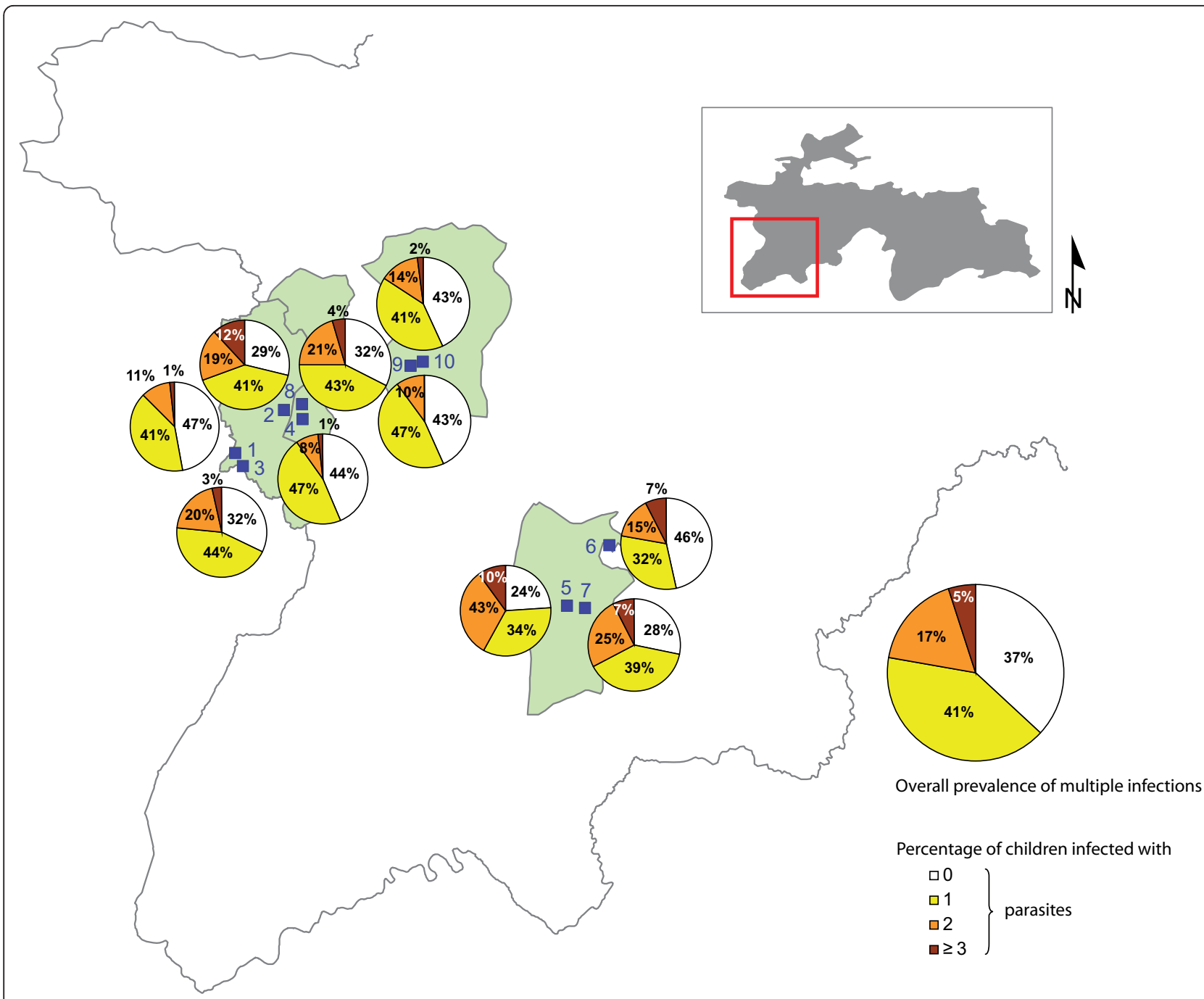

Figure 1 Prevalence of multiple species infection with helminths and pathogenic intestinal protozoa, stratified by school, in western Tajikistan in early 2009

least 50 children per school), and hence obtaining a minimal sample size of 500 fully complying children.

\section{Field procedures}

School directors from the selected schools and teachers of grades 2 and 3 were visited by the survey team 1 week prior to our cross-sectional parasitological and questionnaire surveys. A written informed consent form for the parents/guardians of participating children, a questionnaire for the household heads, and a small plastic container for collection of stool samples were left with the teachers and distributed to eligible children. The questionnaires were pre-tested in a village near Dushanbe, the capital of Tajikistan, and adapted prior to administration.

During the school-based survey, the signed informed consent sheets, household questionnaires and stool samples were collected. Unique identification numbers were assigned to each participating child. A short interview was held with each child, using a questionnaire pertaining to hygiene behaviour, drinking water and sanitation adapted from a standard tool provided by the joint monitoring programme (JPM) of WHO and UNICEF [24]. Each child was weighed to the nearest $\mathrm{kg}$ and measured to the nearest $\mathrm{cm}$. At the end of the survey, each child was given a piece of soap and a small pack of iodine-fortified salt as a small token for their participation.

\section{Laboratory procedures}

From each stool sample, duplicate Kato-Katz thick smears were prepared on microscope slides shortly after stool collection by two experienced laboratory technicians from the Republican Tropical Disease Centre 
(RTDC) [25]. Thick smears were allowed to clear for 4560 min prior to examination under a light microscope for helminth eggs. The number of helminth eggs was counted and recorded for each species separately. The slides were read on the spot and the teachers and directors were informed about the overall prevalence of helminth infections in their school.

In addition, approximately 1-2 g of stool was placed in a Falcon tube filled with $15 \mathrm{ml}$ of sodium acetate-acetic acid-formalin (SAF) [26,27]. These SAF-fixed stool samples were transferred to a specialised laboratory in Italy and examined there by an experienced laboratory technician for the presence of helminths and intestinal protozoa using an ether-concentration technique, adhering to a standard protocol [28].

For quality control purposes, $10 \%$ of the Kato-Katz thick smears were randomly selected and read retrospectively by an experienced laboratory technician in Côte d'Ivoire. A senior laboratory technician from Switzerland checked approximately $5 \%$ of the SAF-fixed stool samples that were examined by the ether-concentration method. In case of discordant results, the slides were re-read and results discussed until agreement between the technicians was reached.

\section{Ethical considerations}

The study was approved by the Ministry of Health $(\mathrm{MoH})$ of Tajikistan (reference no. 16/75-92). The study protocol was presented to the Deputy $\mathrm{MoH}$ and methodological issues related to the survey were discussed with the heads of collaborating partner institutes (RTDC and State Sanitary Hygiene Surveillance Department). The primary health care network managers of each district health centre and the administrative authorities at community level were informed about the study and their consent was obtained. Parents/guardians of participating children signed a written informed consent prior to study enrolment. Participation was voluntary and children were free to withdraw at any time. At the end of the study, each child was offered an anthelminthic treatment (single oral dose of $400 \mathrm{mg}$ albendazole) free of charge [29]. A feedback session for key stakeholders (e.g. representatives from the $\mathrm{MoH}$ and collaboration institutions) was held at the end of the survey to present and discuss the findings and to jointly draft a plan of action.

\section{Statistical analysis}

Data were entered into EpiData version 3.1 (EpiData Association; Odense, Denmark) and internal consistency checks were done. Stata version 10 (Stata Corporation; College Station, TX, USA) was employed for statistical analysis. The children's socioeconomic status was determined using a household-based asset approach that was adapted from previous studies in Tajikistan [11,14]. In brief, a wealth index was constructed by estimating household asset weights by means of a principal component analysis (PCA) methodology [30]. Nine variables were included in the PCA (i.e. frequency of meat consumption, refrigerator, radio, colour television, satellite, DVD recorder, car, mobile phone and fixed line phone). Missing values were replaced with the mean for the corresponding variable [31].

Sources of drinking water were grouped into 'improved' (i.e. piped water into dwelling/yard, public tap or standpipe, protected dug well/spring, bottle water and rainwater) and 'unimproved' sources (i.e. unprotected spring, cart with small tank, tanker truck and surface water) according to a classification used by the JPM of WHO and UNICEF [24].

With regard to the parasitological data, only children who had duplicate Kato-Katz thick smear readings plus results from the ether-concentration test were included in the final analysis. A helminth infection was defined as the presence of at least one helminth egg in one of the two Kato-Katz thick smears and/or the SAF-fixed stool sample. The presence of an intestinal protozoon cyst in the SAF-fixed stool sample subjected to an ether-concentration method was used as our diagnostic approach for these parasites. For helminths, infection intensity at the unit of an individual was determined as the arithmetic mean egg count from two Kato-Katz thick smears, multiplied by a factor 24 to obtain eggs per gram of stool (EPG). Helminth infection intensities were grouped into light (A. lumbricoides, 1-4, 999 EPG; H. nana, 1-1, 999 EPG; T. trichiura, 1-999 EPG); moderate (A. lumbricoides, 5, 000-49, 999; H. nana, 2, 000-9, 999 EPG; T. trichiura, 1, 000-9, 999 EPG); and heavy (A. lumbricoides, 250, 000 EPG; H. nana and T. trichiura, $\geq 10$, 000 EPG) [29,32]. No hookworm eggs were found in the Kato-Katz thick smears. For Enterobius vermicularis, no attempt was made to estimate infection intensity, because the Kato-Katz technique lacks diagnostic accuracy for this helminth species [33]. Children were grouped into three age classes: (i) 7-8 years; (ii) 9 years; and (iii) $10-11$ years.

Proportions were compared using Pearson's $\chi^{2}$ and Fisher's exact test as appropriate. Medians between groups were compared using the Student's $t$-test and Bartlett's test for equal variances, as appropriate. Risk factors for infection with $H$. nana, G. intestinalis and $E$. histolytica/E. dispar were analysed by fitting bi- and multivariate logistic regression models. Explanatory variables associated with infection and a $P$-value $\leq 0.15$ were included into a multivariate logistic regression model. A stepwise backward elimination approach removing covariates above a level of 0.15 one after another was employed. Variations of conditions between schools 
were considered by introducing a school-level random effect. For all tests, 95\% confidence intervals (CIs) were calculated.

\section{Results}

\section{Study compliance}

From a total of 623 children registered in grades 2 and 3 in the 10 selected schools, 602 children participated in the cross-sectional survey, owing to an overall compliance of $96.6 \%$. Reasons for non-compliance were absence due to recent travels $(n=9)$, absence of written informed consent $(\mathrm{n}=3)$, feeling unwell $(\mathrm{n}=2)$ or no specific reason $(n=7)$. Children's age ranged between 7 and 11 years with a mean of 9.1 years. There was a borderline significant age difference between schools (Bartlett's test for equal variances: $\chi^{2}=16.54$, degree of freedom (d.f.) $=$ $9, P=0.056)$. There were slightly more boys than girls (311 versus $291, P=0.416$ ) with no sex difference between schools $\left(\chi^{2}=10.47\right.$, d.f. $\left.=9, P=0.314\right)$.

\section{Household profiles}

One quarter $(24.5 \%)$ of the variability of the household's socioeconomic status was explained by the first principal component. Greatest weight was given to households possessing a car (0.44), refrigerator (0.42) and DVD recorder (0.36). After standardising the asset weighed variables, households having a satellite (0.79), refrigerator (0.72) and car (0.64) were scored highest, whereas lowest scores were given to households with no colour television (-0.63), no mobile phone (-0.47) and no DVD recorder (-0.44). A wealth index was created for each child by building a total of all household asset scores and assigning accordingly each child into five wealth quintiles. Finally, each child was grouped into three wealth classes (bottom, 40\%; middle, $40 \%$; top, $20 \%$ ) (Table 1).

Most households comprised between 6 and 10 individuals. Every fifth household was smaller, counting 3-5 individuals. Large households with 11 persons and more accounted for $10 \%$ in our study sample. Two-thirds of the household heads were farmers or craftspeople. Regarding educational attainment, every other household head obtained a secondary school-leaving certificate (11 years of school or more), whereas almost every third had a university degree. Only $3 \%$ of the household heads reported not having received any education. With few exceptions, all households kept livestock, such as bullocks, cows, donkeys, goats, horses and sheep. In addition, half of the households kept chickens. Meat was consumed, on average, twice a week.

Slightly more than half of the households (53\%) had improved drinking water sources, such as protected springs (20\%) and public tap/standpipe (18\%). The remaining $47 \%$ of the households depended on unimproved sources, i.e. surface water from irrigation canals, rivers and streams (38\%), unprotected wells and springs and rain water. There was large heterogeneity of unimproved water sources at the unit of school, varying between $2 \%$ and $100 \%$. With regard to sanitation, almost all households used pit latrines that are not connected to a sewage system. Three out of four households had their own latrines, whereas the remaining households shared sanitation facilities with their neighbours in the yard. Two households used a public sanitation facility.

\section{Helminths and intestinal protozoa infections}

Overall, 599 of the interviewed children had a single stool sample subjected to duplicate Kato-Katz thick

Table 1 Wealth quintiles based on nine household assets for 602 children aged 7-11 years from 10 schools in western Tajikistan, early 2009

\begin{tabular}{|c|c|c|c|c|}
\hline \multirow[b]{2}{*}{ Household asset variable } & \multicolumn{4}{|c|}{ Wealth quintiles (\%) } \\
\hline & Total & $\begin{array}{l}\text { Bottom } 40 \% \\
(n=257)\end{array}$ & Middle $40 \%(n=225)$ & Top $20 \%(n=120)$ \\
\hline \multicolumn{5}{|l|}{ Meat consumption } \\
\hline$\geq 5$ times a week & 10.6 & 4.3 & 9.3 & 26.7 \\
\hline 3-4 times a week & 16.0 & 5.5 & 22.2 & 26.7 \\
\hline 1-2 times a week & 47.2 & 51.0 & 48.0 & 37.5 \\
\hline$<1$ times a week & 26.3 & 39.3 & 20.4 & 9.2 \\
\hline Has a refrigerator & 24.6 & 2.7 & 22.2 & 75.8 \\
\hline Has a radio & 60.8 & 40.9 & 66.2 & 93.3 \\
\hline Has a colour television & 78.9 & 59.1 & 92.9 & 94.2 \\
\hline Has a satellite & 12.3 & 1.6 & 9.3 & 40.8 \\
\hline Has a DVD recorder & 58.1 & 33.5 & 74.7 & 86.7 \\
\hline Has a car & 31.9 & 3.5 & 35.6 & 85.8 \\
\hline Has mobile phone & 68.4 & 46.7 & 83.6 & 86.7 \\
\hline Has a fix phone & 9.5 & 2.3 & 8.4 & 26.7 \\
\hline
\end{tabular}


smear reading and 594 of the children had a small portion of stool fixed in SAF that was examined by an ether-concentration technique for helminths and intestinal protozoa. Complete parasitological data were therefore available for a subsample of 594 participants. Table 2 shows that the prevalence of infection with any helminths or pathogenic intestinal protozoa was $32.0 \%$ and $47.1 \%$, respectively. The overall prevalence of soil-transmitted helminths was $8.6 \%$. There was no statistically significant sex difference in the prevalence of any of the helminths identified $(P>0.05)$. H. nana was the predominant helminth species (25.8\%), whereas all other helminths identified showed prevalences below $5 \%$, e.g. A. lumbricoides (4.4\%), hookworm (3.5\%) and T. trichiura (1.4\%). With regard to age, A. lumbricoides showed a statistically significantly higher prevalence in the youngest children (age 7-8 years, prevalence $9.0 \%$ versus 3.8\% and $2.2 \%$ in 9 -year-old and 10- to 11-year-old children; Fisher's exact test, $P=0.021$ ).

With regard to intestinal protozoa, the most common species was the non-pathogenic Entamoeba coli (65.7\%). The pathogenic protozoa G. intestinalis and E. histolytica/E. dispar were detected in $26.4 \%$ and $25.9 \%$ of the children, respectively. The prevalence of the suspected pathogenic protozoon Blastocystis hominis was $19.9 \%$. No sex-related differences were found for any of the intestinal protozoa identified.

The prevalence of single and multiple helminths and pathogenic intestinal protozoa species infections are displayed in Figure 1. Overall, 40.9\% of all children had a single species infection, whereas $17.3 \%$ had a dual species infection and $4.9 \%$ harboured at least three intestinal pathogenic parasite species concurrently. There was considerable heterogeneity of overall infection prevalence between schools, ranging from $53.1 \%$ to $76.0 \%$. Prevalence of multiple species infection across schools was between $9.7 \%$ and $42.0 \%$. The youngest age group (7-8 years) exhibited a slightly higher infection prevalence of multiple species infection than their older counterparts, but the difference was not statistically significant (Fisher's exact, $P=0.061$ ).

\section{Spatial distribution of intestinal parasite infections}

The overall prevalence of any intestinal parasites (pathogenic and non-pathogenic) was $88.2 \%$, ranging from $76.7 \%$ to $93.2 \%$ across schools. Twenty-seven children (4.6\%) were infected with helminths only, with prevalences ranging from $1.7 \%$ to $7.8 \%$ at the unit of the school. More than half of the children were infected with intestinal protozoa only $(56.2 \%, \mathrm{n}=334)$, with a range from $38.0 \%$ to $64.1 \%$ in individual schools. A total of 163 children (27.4\%) harboured helminths and intestinal protozoa concurrently, between $18.3 \%$ and $54.0 \%$ at the unit of the school.
Most widespread co-infections were combinations with $H$. nana and G. intestinalis (5.2\%), followed by $H$. nana and E. histolytica/E. dispar (3.9\%). The most common triple infection was $H$. nana, E. histolytica/E. dispar and G. intestinalis (1.5\%).

The prevalence of species-specific helminths and intestinal protozoa infections, stratified by school, is given in Table 2. H. nana showed highest infection prevalence exceeding $30 \%$ in four schools. The highest infection prevalence of $H$. nana (38.0\%) occurred in a school where the highest prevalence of $A$. lumbricoides (16.0\%) and hookworm (10.0\%) were also observed. $T$. trichiura infections were found only in two schools (8.5\% and 6.0\%). Regarding intestinal protozoa infections, prevalences exceeding $30 \%$ were observed in two schools for G. intestinalis (40.7\% and 32.8\%) and in two schools for E. histolytica/E. dispar (38.0\% and 31.3\%). The peak prevalence of E. histolytica/E. dispar was observed in the school where the highest helminth infection prevalence was noted.

\section{Helminth infection intensities}

Helminth infection intensities were estimated based on duplicate Kato-Katz thick smears. The overall geometric mean faecal egg count for H. nana was 383 EPG (95\% CI: 311-471 EPG), for A. lumbricoides it was 223 EPG (95\% CI: 154-321 EPG), and the respective estimate for T. trichiura was 125 EPG (95\% CI: 71-222 EPG). All infections were of light intensity according to WHO cut-offs.

There was no statistically significant difference in infection intensity between boys and girls for $H$. nana (two-sample $t$-test, $t=-0.014$, d.f. $=71, P=0.989$ ) and A. lumbricoides $(t=0.020$, d.f. $=19, P=0.984)$. Infection intensity of $H$. nana decreased with age (ANOVA, Bartlett's test for equal variances, d.f. $=71,2 ; \chi^{2}(2)=$ $11.50, P=0.003)$. While the geometric mean faecal egg count of $H$. nana for children aged 7-8 years was 460 EPG (95\% CI: 278-762 EPG), it was 401 EPG in 9-yearold children (95\% CI: 297-541 EPG), and 308 EPG in the oldest age group investigated (95\% CI: 210-450 EPG). Age-related differences were also found for $A$. lumbricoides (ANOVA, Bartlett's test for equal variances, d.f. $\left.=18,2 ; \chi^{2}(2)=8.55, P=0.014\right)$. The highest geometric mean faecal egg count was observed for 9year-old children (290 EPG, 95\% CI: 120-701 EPG), whereas lower faecal egg counts were observed for younger and older children (7-8 years, mean 215 EPG, 95\% CI: 133-348 EPG; 10-11 years, mean 153 EPG, 95\% CI: 38-610 EPG).

\section{Risk factors for intestinal parasites}

Table 3 summarises demographic, socioeconomic, hygiene- and drinking water source-related risk factors 
Table 2 Number (\%) of schoolchildren infected with helminths and intestinal protozoa in western Tajikistan, early 2009

\begin{tabular}{|c|c|c|c|c|c|c|c|c|c|c|c|c|c|c|c|}
\hline Parasite & $\begin{array}{l}\text { Overall } \\
(\mathrm{n}=594)\end{array}$ & $\begin{array}{l}\text { Boys } \\
(n=307)\end{array}$ & $\begin{array}{l}\text { Girls } \\
(n=287)\end{array}$ & $\chi^{2}$ & $\begin{array}{l}P \text { - } \\
\text { value }\end{array}$ & $\begin{array}{l}\text { School } \\
\text { no. } 1 \\
(n=64)\end{array}$ & $\begin{array}{l}\text { School } \\
\text { no. } 2 \\
(n=59)\end{array}$ & $\begin{array}{l}\text { School } \\
\text { no. } 3 \\
(n=59)\end{array}$ & $\begin{array}{l}\text { School } \\
\text { no. } 4 \\
(n=62)\end{array}$ & $\begin{array}{l}\text { School } \\
\text { no. } 5 \\
(n=50)\end{array}$ & $\begin{array}{l}\text { School } \\
\text { no. } 6 \\
(n=54)\end{array}$ & $\begin{array}{l}\text { School } \\
\text { no. } 7 \\
(n=67)\end{array}$ & $\begin{array}{l}\text { School } \\
\text { no. } 8 \\
(n=68)\end{array}$ & $\begin{array}{l}\text { School } \\
\text { no. } 9 \\
(n=60)\end{array}$ & $\begin{array}{l}\text { School } \\
\text { no. } 10 \\
(n=51)\end{array}$ \\
\hline \multicolumn{16}{|l|}{ Helminth } \\
\hline Hymenolepis nana, $a^{\mathrm{a}, \mathrm{b}}$ & $153(25.8)$ & $74(24.1)$ & $79(27.5)$ & 0.91 & 0.341 & $11(17.2)$ & $19(32.2)$ & $17(28.8)$ & $13(21.0)$ & 19 (38.0) & $11(20.4)$ & $23(34.3)$ & $23(33.8)$ & $6(10.0)$ & $11(21.6)$ \\
\hline Ascaris lumbricoides, ${ }^{a}$ & $26(4.4)$ & $16(5.2)$ & $10(3.5)$ & NA & 0.323 & $3(4.7)$ & 0 & $1(1.7)$ & 0 & $8(16.0)$ & $4(7.4)$ & $4(6.0)$ & $4(5.9)$ & 0 & $2(3.9)$ \\
\hline Hookworm ${ }^{a, b}$ & $21(3.5)$ & $10(3.3)$ & $11(3.8)$ & NA & 0.825 & 0 & $4(6.8)$ & 0 & 0 & $5(10.0)$ & $2(3.7)$ & $3(4.5)$ & $2(2.9)$ & $4(6.7)$ & $1(2.0)$ \\
\hline Enterobius vermicularis ${ }^{\mathrm{a}, \mathrm{b}}$ & $15(2.5)$ & $4(1.3)$ & $11(3.8)$ & NA & 0.066 & $2(3.1)$ & $1(1.7)$ & $6(10.2)$ & $1(1.6)$ & $2(4.0)$ & 0 & $2(3.0)$ & $1(1.5)$ & 0 & 0 \\
\hline Trichuris trichiura, ${ }^{\mathrm{a}, \mathrm{b}}$ & $8(1.4)$ & $2(0.7)$ & $6(2.1)$ & NA & 0.164 & 0 & $5(8.5)$ & 0 & 0 & $3(6.0)$ & 0 & 0 & 0 & 0 & 0 \\
\hline Fasciola hepatica, b & $3(0.5)$ & $2(0.7)$ & $1(0.4)$ & NA & 0.999 & $1(1.6)$ & $1(1.7)$ & 0 & 0 & 0 & 0 & $1(1.5)$ & 0 & 0 & 0 \\
\hline Hymenolepis diminuta ${ }^{a}$ & $3(0.5)$ & $2(0.7)$ & $1(0.4)$ & NA & 0.999 & 0 & 0 & 0 & 0 & 0 & $2(3.7)$ & 0 & 0 & $1(1.7)$ & 0 \\
\hline Dicrocoelium dendriticum ${ }^{a}$ & $1(0.2)$ & 0 & $1(0.3)$ & NA & 0.483 & 0 & 0 & 0 & 0 & 0 & 0 & 0 & 0 & $1(1.7)$ & 0 \\
\hline Any helminth & $190(32.0)$ & $91(29.6)$ & $99(34.5)$ & 1.61 & 0.205 & $15(23.4)$ & $21(35.6)$ & $22(37.3)$ & $13(21.0)$ & $27(54.0)$ & $14(25.9)$ & $29(43.3)$ & $26(38.2)$ & $11(18.3)$ & $12(23.5)$ \\
\hline Any soil-transmitted helminth & $51(8.6)$ & $27(8.8)$ & $24(0.4)$ & NA & 0.851 & $3(4.7)$ & $9(15.3)$ & $1(1.7)$ & 0 & $13(26.0)$ & $5(9.3)$ & $7(10.5)$ & $6(8.8)$ & $4(6.7)$ & $3(5.9)$ \\
\hline \multicolumn{16}{|l|}{ Intestinal protozoon } \\
\hline Entamoeba colic & $390(65.7)$ & $196(63.8)$ & $194(67.6)$ & 0.93 & 0.336 & $41(64.1)$ & $36(61.0)$ & $47(79.7)$ & $42(67.7)$ & $36(72.0)$ & $38(70.4)$ & $47(70.2)$ & $41(62.3)$ & $31(51.7)$ & $31(60.8)$ \\
\hline Giardia intestinalis ${ }^{\mathrm{a}}$ & $157(26.4)$ & $82(26.7)$ & $75(26.1)$ & 0.03 & 0.873 & $7(10.9)$ & $24(40.7)$ & $16(27.1)$ & $17(27.4)$ & $12(24.0)$ & $12(22.2)$ & $22(32.8)$ & $16(23.5)$ & $18(30.0)$ & $13(25.5)$ \\
\hline Entamoeba histolytica/E. dispar ${ }^{a}$ & $154(25.9)$ & $82(26.7)$ & $72(25.1)$ & 0.20 & 0.652 & $19(29.7)$ & $13(22.0)$ & $16(27.1)$ & $11(17.7)$ & $19(38.0)$ & $14(25.9)$ & $21(31.3)$ & $20(29.4)$ & $10(16.7)$ & $11(21.6)$ \\
\hline Blastocystis hominis $^{d}$ & $118(19.9)$ & $63(20.5)$ & $55(19.2)$ & 0.17 & 0.679 & $12(18.8)$ & $11(18.6)$ & $13(22.0)$ & $11(17.7)$ & $9(18.0)$ & $8(14.8)$ & $15(22.4)$ & $17(25.0)$ & $13(21.7)$ & $9(17.7)$ \\
\hline Endolimax nana ${ }^{c}$ & $118(19.9)$ & $61(19.9)$ & $57(19.9)$ & 0.00 & 0.998 & $13(20.3)$ & $11(18.6)$ & $18(30.5)$ & $7(11.3)$ & $9(18.0)$ & $7(13.0)$ & $19(28.4)$ & $17(25.0)$ & $8(13.3)$ & $9(17.7)$ \\
\hline lodamoeba bütschlii' & $29(4.9)$ & $13(4.2)$ & $16(5.6)$ & NA & 0.455 & $4(6.3)$ & 0 & $6(10.1)$ & 0 & $4(8.0)$ & $6(11.1)$ & $4(6.0)$ & $3(4.4)$ & 0 & $2(3.9)$ \\
\hline Entamoeba hartmannic & $28(4.7)$ & $14(4.6)$ & $14(4.9)$ & NA & 0.855 & $4(6.3)$ & $3(5.1)$ & $2(3.4)$ & $4(6.5)$ & $4(8.0)$ & $2(3.7)$ & $3(4.5)$ & $3(4.4)$ & $1(1.7)$ & $2(3.9)$ \\
\hline Chilomastix mesnilic & $25(4.2)$ & $15(4.9)$ & $10(3.5)$ & NA & 0.677 & $2(3.1)$ & $3(5.1)$ & $2(3.4)$ & 0 & 0 & $8(14.8)$ & $4(6.0)$ & $5(7.4)$ & $1(1.7)$ & 0 \\
\hline Any intestinal protozoa & $497(83.7)$ & $255(83.1)$ & $242(84.3)$ & 0.17 & 0.678 & $53(82.8)$ & $53(89.8)$ & $54(91.5)$ & $50(80.7)$ & $44(88.0)$ & $46(85.2)$ & 60 (89.6) & $56(82.4)$ & $42(70.0)$ & $39(76.5)$ \\
\hline Any pathogenic intestinal protozoa & $280(47.1)$ & $148(48.2)$ & $132(46.0)$ & 0.29 & 0.589 & $25(39.1)$ & $33(55.9)$ & $29(58.0)$ & $26(41.9)$ & $29(58.0)$ & $22(40.7)$ & $36(53.7)$ & $33(48.5)$ & $26(43.3)$ & $21(41.2)$ \\
\hline $\begin{array}{l}\text { Overall infection prevalence with } \\
\text { pathogenic intestinal parasites }\end{array}$ & $375(63.1)$ & $195(63.5)$ & $180(62.7)$ & 0.04 & 0.840 & $34(53.1)$ & $42(71.2)$ & $40(67.8)$ & $35(56.5)$ & $38(76.0)$ & $29(53.7)$ & $48(71.6)$ & $46(67.7)$ & $34(56.7)$ & $29(56.9)$ \\
\hline
\end{tabular}

pathogenic inte

${ }^{\text {a Pathogenic }}$

${ }^{\mathrm{b}}$ Pooled results from duplicate Kato-Katz thick smear readings and ether-concentration test results

c Non-pathogenic

d Suspected pathogenic

NA $P$-value based on Fisher's exact test 
Table 3 Results from bivariate non-random and random effects multivariate logistic regression models for risk factors of specific intestinal parasitic infections among schoolchildren in western Tajikistan, early 2009

\begin{tabular}{|c|c|c|c|c|c|c|c|c|c|c|c|c|c|c|c|c|c|c|}
\hline \multirow[t]{3}{*}{ Explanatory variable } & \multicolumn{6}{|c|}{ Giardia intestinalis } & \multicolumn{6}{|c|}{ Entamoeba histolytica/E. dispar } & \multicolumn{6}{|c|}{ Hymenolepis nana } \\
\hline & \multicolumn{3}{|c|}{ Bivariate model $^{\mathrm{a}}$} & \multicolumn{3}{|c|}{ Multivariate model $^{\mathbf{b}}$} & \multicolumn{3}{|c|}{ Bivariate model $^{\mathrm{a}}$} & \multicolumn{3}{|c|}{ Multivariate model ${ }^{\mathbf{b}}$} & \multicolumn{3}{|c|}{ Bivariate model $^{\mathrm{a}}$} & \multicolumn{3}{|c|}{ 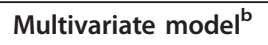 } \\
\hline & OR & $(95 \% \mathrm{Cl})$ & P-value ${ }^{c}$ & OR & $95 \% \mathrm{Cl}$ & P-value & OR & $\begin{array}{l}(95 \% \\
\mathrm{Cl})\end{array}$ & P-value ${ }^{c}$ & OR & $95 \% \mathrm{Cl}$ & P-value ${ }^{c}$ & OR & $95 \% \mathrm{Cl}$ & $P$-value ${ }^{c}$ & OR & $95 \% \mathrm{Cl}$ & P-value \\
\hline \multicolumn{19}{|l|}{ Demography } \\
\hline \multicolumn{19}{|l|}{ Sex } \\
\hline Male & 1.00 & & & & & & 1.00 & & & & & & 1.00 & & & & & \\
\hline Female & 0.97 & $\begin{array}{l}(0.68, \\
1.40)\end{array}$ & 0.889 & & & & 0.91 & $\begin{array}{l}(0.64, \\
1.33)\end{array}$ & 0.652 & & & & 1.27 & $\begin{array}{l}(0.87 \\
1.86)\end{array}$ & 0.211 & & & \\
\hline \multicolumn{19}{|l|}{ Age (years) } \\
\hline $7-8$ & 1.00 & & & & & & 1.00 & & & & & & 1.00 & & & & & \\
\hline 9 & 0.74 & $\begin{array}{l}(0.46 \\
1.18)\end{array}$ & & & & & 0.73 & $\begin{array}{l}(0.45 \\
1.17)\end{array}$ & & & & & 0.91 & $\begin{array}{l}(0.56, \\
1.49)\end{array}$ & & & & \\
\hline $10-11$ & 0.79 & $\begin{array}{l}(0.48 \\
1.30)\end{array}$ & 0.440 & & & & 0.80 & $\begin{array}{l}(0.48, \\
1.34)\end{array}$ & 0.421 & & & & 0.80 & $\begin{array}{l}(0.47 \\
1.36)\end{array}$ & 0.695 & & & \\
\hline \multicolumn{19}{|l|}{ Socioeconomic status } \\
\hline Bottom 40\% & 1.00 & & & & & & 1.00 & & & & & & 1.00 & & & 1.00 & & \\
\hline Middle 40\% & 1.00 & $\begin{array}{l}(0.66, \\
1.51)\end{array}$ & & & & & 0.82 & $\begin{array}{l}(0.55 \\
1.24)\end{array}$ & & & & & 0.58 & $\begin{array}{l}(0.38, \\
0.90)\end{array}$ & & 0.69 & $\begin{array}{l}(0.42, \\
1.12)\end{array}$ & \\
\hline Top 20\% & 1.22 & $\begin{array}{l}(0.75 \\
1.99)\end{array}$ & 0.680 & & & & 0.55 & $\begin{array}{l}(0.32, \\
0.93)\end{array}$ & 0.075 & & & & 0.88 & $\begin{array}{l}(0.53, \\
1.46)\end{array}$ & 0.046 & 1.06 & $\begin{array}{l}(0.60, \\
1.87)\end{array}$ & 0.223 \\
\hline \multicolumn{19}{|l|}{ Weekly meat consumption } \\
\hline$<1$ times per week & 0.61 & $\begin{array}{l}(0.40 \\
0.94)\end{array}$ & 0.022 & 0.70 & $\begin{array}{l}(0.45 \\
1.09)\end{array}$ & 0.112 & & & & & & & & & & & & \\
\hline 3-4 times per week & & & & & & & & & & & & & 0.66 & $\begin{array}{l}(0.39, \\
1.12)\end{array}$ & 0.112 & 0.76 & $\begin{array}{l}(0.43, \\
1.35)\end{array}$ & 0.125 \\
\hline$\geq 5$ times per week & & & & & & & 0.57 & $\begin{array}{l}(0.29, \\
1.12)\end{array}$ & 0.084 & & & & & & & & & \\
\hline \multicolumn{19}{|l|}{ Livestock } \\
\hline No livestock & 0.60 & $\begin{array}{l}(0.30 \\
1.19)\end{array}$ & 0.130 & 0.51 & $\begin{array}{l}(0.24 \\
1.11)\end{array}$ & 0.072 & & & & & & & 0.51 & $\begin{array}{l}(0.24, \\
1.06)\end{array}$ & 0.056 & & & \\
\hline Bullock & 1.60 & $\begin{array}{l}(0.91 \\
2.83)\end{array}$ & 0.110 & 1.63 & $\begin{array}{l}(0.87 \\
3.07)\end{array}$ & 0.131 & 0.64 & $\begin{array}{l}(0.32, \\
1.26)\end{array}$ & 0.178 & 0.58 & $\begin{array}{l}(0.27 \\
1.24)\end{array}$ & 0.143 & 0.58 & $\begin{array}{l}(0.28, \\
1.19)\end{array}$ & 0.121 & 0.76 & $\begin{array}{l}(0.35 \\
1.64)\end{array}$ & 0.169 \\
\hline Horse/donkey & & & & & & & 1.48 & $\begin{array}{l}(0.99, \\
2.22)\end{array}$ & 0.056 & & & & & & & & & \\
\hline Goat & & & & & & & 1.34 & $\begin{array}{l}(0.89, \\
2.01)\end{array}$ & 0.170 & & & & & & & & & \\
\hline Sheep & 0.71 & $\begin{array}{l}(0.45 \\
1.14)\end{array}$ & 0.146 & & & & 1.61 & $\begin{array}{l}(1.05 \\
2.48)\end{array}$ & 0.030 & & & & 0.73 & $\begin{array}{l}(0.46, \\
1.17)\end{array}$ & 0.180 & 0.71 & $\begin{array}{l}(0.43, \\
1.18)\end{array}$ & 0.089 \\
\hline Poultry & & & & & & & 1.54 & $\begin{array}{l}(1.05, \\
2.25)\end{array}$ & 0.027 & 1.43 & $\begin{array}{l}(0.95 \\
2.14)\end{array}$ & 0.089 & 1.95 & $\begin{array}{l}(1.31 \\
2.90)\end{array}$ & $<0.001$ & 2.04 & $\begin{array}{l}(1.34, \\
3.12)\end{array}$ & 0.001 \\
\hline
\end{tabular}


Table 3 Results from bivariate non-random and random effects multivariate logistic regression models for risk factors of specific intestinal parasitic infections among schoolchildren in western Tajikistan, early 2009 (Continued)

\begin{tabular}{|c|c|c|c|c|c|c|c|c|c|c|c|c|c|c|c|c|c|c|}
\hline $\begin{array}{l}\text { Washing hands after defecation } \\
\text { with soap }\end{array}$ & & & & & & & & & & & & & & & & & & \\
\hline Rarely/sometimes & 1.00 & & & & & & 1.00 & & & & & & 1.00 & & & & & \\
\hline Often/always & 1.14 & $\begin{array}{l}(0.95 \\
1.37)\end{array}$ & 0.160 & & & & 1.15 & $\begin{array}{l}(0.96 \\
1.39)\end{array}$ & 0.134 & & & & 1.14 & $\begin{array}{l}(0.94 \\
1.39)\end{array}$ & 0.182 & & & \\
\hline \multicolumn{19}{|l|}{ Eating unpeeled fruits } \\
\hline Rarely/sometimes & & & & & & & 1.00 & & & 1.00 & & & & & & & & \\
\hline Often/always & & & & & & & 0.83 & $\begin{array}{l}(0.68, \\
1.02)\end{array}$ & 0.073 & 0.86 & $\begin{array}{l}(0.69, \\
1.07)\end{array}$ & 0.177 & & & & & & \\
\hline \multicolumn{19}{|l|}{ Eating raw vegetables } \\
\hline Rarely/sometimes & & & & & & & 1.00 & & & & & & & & & & & \\
\hline Often/always & & & & & & & 1.43 & $\begin{array}{l}(0.97 \\
2.12)\end{array}$ & 0.076 & & & & & & & & & \\
\hline $\begin{array}{l}\text { Wearing sandals outside in } \\
\text { summer }\end{array}$ & 0.30 & $\begin{array}{l}(0.11 \\
0.84)\end{array}$ & 0.024 & & & & & & & & & & & & & & & \\
\hline $\begin{array}{l}\text { Wearing closed shoes outside } \\
\text { in summer }\end{array}$ & 3.39 & $\begin{array}{l}(1.12 \\
10.25)\end{array}$ & 0.033 & 3.26 & $\begin{array}{l}(1.01 \\
10.43)\end{array}$ & 0.047 & & & & & & & & & & & & \\
\hline \multicolumn{19}{|l|}{ Sanitation } \\
\hline Toilet in household & 0.70 & $\begin{array}{l}(0.47 \\
1.03)\end{array}$ & 0.077 & & & & 0.76 & $\begin{array}{l}(0.51 \\
1.14)\end{array}$ & 0.192 & & & & & & & & & \\
\hline Toilet in yard & 1.47 & $\begin{array}{l}(0.99, \\
2.19)\end{array}$ & 0.060 & 1.37 & $\begin{array}{l}(0.88 \\
2.13)\end{array}$ & 0.163 & 1.33 & $\begin{array}{l}(0.89, \\
1.98)\end{array}$ & 0.173 & 1.39 & $\begin{array}{l}(0.89, \\
2.18)\end{array}$ & 0.149 & & & & & & \\
\hline \multicolumn{19}{|l|}{ Source of drinking water } \\
\hline $\begin{array}{l}\text { Water tap in yard (shared with } \\
\text { neighbours) }\end{array}$ & & & & & & & 1.90 & $\begin{array}{l}(0.95 \\
3.81)\end{array}$ & 0.079 & & & & & & & & & \\
\hline Public tap/standpipe & 0.35 & $\begin{array}{l}(0.12 \\
1.00)\end{array}$ & 0.027 & 0.27 & $\begin{array}{l}(0.05 \\
1.39)\end{array}$ & 0.094 & & & & & & & 0.42 & $\begin{array}{l}(0.16, \\
1.11)\end{array}$ & 0.056 & 0.37 & $\begin{array}{l}(0.12, \\
1.13)\end{array}$ & 0.057 \\
\hline Protected spring & & & & & & & 0.52 & $\begin{array}{l}(0.31 \\
0.88)\end{array}$ & 0.010 & 0.41 & $\begin{array}{l}(0.23, \\
0.74)\end{array}$ & 0.002 & 0.42 & $\begin{array}{l}(0.20, \\
0.88)\end{array}$ & 0.013 & 0.44 & $\begin{array}{l}(0.20 \\
0.97)\end{array}$ & 0.020 \\
\hline Surface water: river & & & & & & & 1.57 & $\begin{array}{l}(0.97 \\
2.52)\end{array}$ & 0.071 & & & & & & & & & \\
\hline Surface water: stream & & & & & & & 0.35 & $\begin{array}{l}(0.08, \\
1.53)\end{array}$ & 0.113 & 0.27 & $\begin{array}{l}(0.06, \\
1.24)\end{array}$ & 0.054 & & & & & & \\
\hline Surface water: river/stream & & & & & & & & & & & & & 1.36 & $\begin{array}{l}(0.86, \\
2.14)\end{array}$ & 0.195 & & & \\
\hline
\end{tabular}

a Crude odds ratio

${ }^{\mathrm{b}}$ School-level random effect included

C $P$-value based on likelihood ratio test (LRT

* Outcome: G. intestinalis, E. histolytica/E. dispar and H. nana. Explanatory variables: demographic, socioeconomic, hygiene behaviour and sources of drinking water. 
for an infection with G. intestinalis, E. histolytica/E. dispar and $H$. nana according to bivariate and multivariate random effects models. Regarding drinking water sources, use of public tap/standpipe (odds ratio $(\mathrm{OR})=$ 0.35, 95\% CI: 0.12-1.00) emerged as a protective factor in the bivariate model for infection with G. intestinalis. Protected spring water was a protective factor for $E$. histolytica/E. dispar infections in the bi- and multivariate model $(\mathrm{OR}=0.52,95 \% \mathrm{CI}: 0.31-0.88$; OR $=0.41,95 \%$ CI: $0.23-0.74$, respectively). Moreover, protected spring water emerged as protecting factor for $H$. nana infections in the bi- and multivariate model $(\mathrm{OR}=0.42,95 \%$ CI: $0.20-0.88$; OR $=0.44,95 \%$ CI: 0.20-0.97).

Children belonging to households keeping sheep and poultry were at a slightly higher risk of an E. histolytica/ E. dispar infection $(\mathrm{OR}=1.61,95 \% \mathrm{CI}: 1.05-2.48$; $\mathrm{OR}=$ 1.54, 95\% CI: 1.05-2.25, respectively). Likewise, $H$. nana infection was associated with chicken farming both in the bi- and multivariate model $(\mathrm{OR}=1.95 .95 \% \mathrm{CI}$ : 1.31-2.90; OR $=2.04,95 \%$ CI: 1.34-3.12). Socioeconomic status was significantly associated with $H$. nana infection, since children from households of the middle $40 \%$ were less likely to be infected compared to their poorer counterparts $(\mathrm{OR}=0.58,95 \%$ CI: $0.38-0.90)$.

\section{Discussion}

The present cross-sectional survey determining the prevalence (and intensity) of infection with helminths and intestinal protozoa among 594 children aged 7-11 years in 10 randomly selected schools in western Tajikistan revealed that parasitic infections are a public health issue. Indeed, every third child was infected with helminths and almost every second child harboured at least one intestinal protozoon species. One out of five children had multiple species intestinal parasitic infections. Every fourth child was infected with $H$. nana, G. intestinalis and E. histolytica/E. dispar. The patterns of intestinal parasitic infections indicated spatial clustering: the school with the highest overall and multiple species infection prevalence showed the highest prevalences of $H$. nana, A. lumbricoides, hookworm and E. histolytica/ E. dispar. Public well/standpipe as drinking water source was found to be a protective factor for G. intestinalis infections, whereas protected spring water reduced the risk of infections with $H$. nana and $E$. histolytica/E. dispar. Children from households keeping poultry were more likely to be infected with $H$. nana and $E$. histolytica/E. dispar than children from the remaining households.

The high overall prevalence of intestinal parasites, observed in our study, corroborates previous studies from Central Asia. A population-representative survey in children aged 6-15 years from Kyrgyzstan demonstrated an overall infection prevalence of $41 \%$ [7].
Unpublished parasitological data from surveys conducted by the Sanitary Epidemiological Service of Kyrgyzstan among 3, 427 school-aged children in 2006/ 2007 indicated an overall infection prevalence of $71.4 \%$, with G. intestinalis being the most common intestinal protozoon species in that study (23.1\%) [34]. Another school-based cross-sectional survey from Afghanistan showed that $47.6 \%$ of the subjects were infected with at least one soil-transmitted helminth, predominantly $A$. lumbricoides (40.9\%) [35]. According to a recent WHO report, prevalence of soil-transmitted helminth infections in Tajikistan was estimated to range between $20 \%$ and $50 \%[10]$.

Significant spatial heterogeneity in the prevalence across schools was found, particularly for helminth infections. Lowest prevalences were found in the two schools in the mountainous area. Spatial disparities of infection prevalence were also described from schoolbased surveys in Haiti [36]. Geographical variation of different soil-transmitted helminths in a study from Zanzibar was interpreted with predominant soil types as a distinguishing factor [37]. Eight schools in our study are located in the ecological zone 'lowland', containing fine-grained alluvial or loessic soils [21] where intensive irrigated agriculture is practiced [38]. The observed clustering of intestinal parasites (i.e. H. nana, A. lumbricoides, hookworm and E. histolytica/E. dispar) in one of the investigated schools corroborates findings of smallscale clustering (e.g. household level). A. lumbricoides and T. trichiura were observed to aggregate at household level in a cross-sectional survey conducted in the People's Republic of China [39]. Another study, conducted in rural Amazonian settlements, observed that almost half of the helminth infections were concentrated in only $5 \%$ of the surveyed households [40]. Some authors differentiated between domestic (household area) and public transmission sites (public places of work, streets, fields and schools) and recommended that control measures should target both domains [41].

Nearly half of all drinking water sources reported by the children in the current study were classified as unimproved sources, but a large variation was found (2$100 \%$ at the unit of the school). Teachers explained that electricity in their villages is often unstable and available only for a few hours per day, particularly during the winter season. When community water supply systems operated by electric pumps are interrupted, people draw water for domestic needs from open and unprotected sources such as irrigation canals and rivers. A large part of the latrines in the schools visited were inappropriately maintained (Figure 2).

Our findings underline UNICEF estimations from 2007; almost half of the rural households in Tajikistan depended on unimproved drinking water sources [42]. 

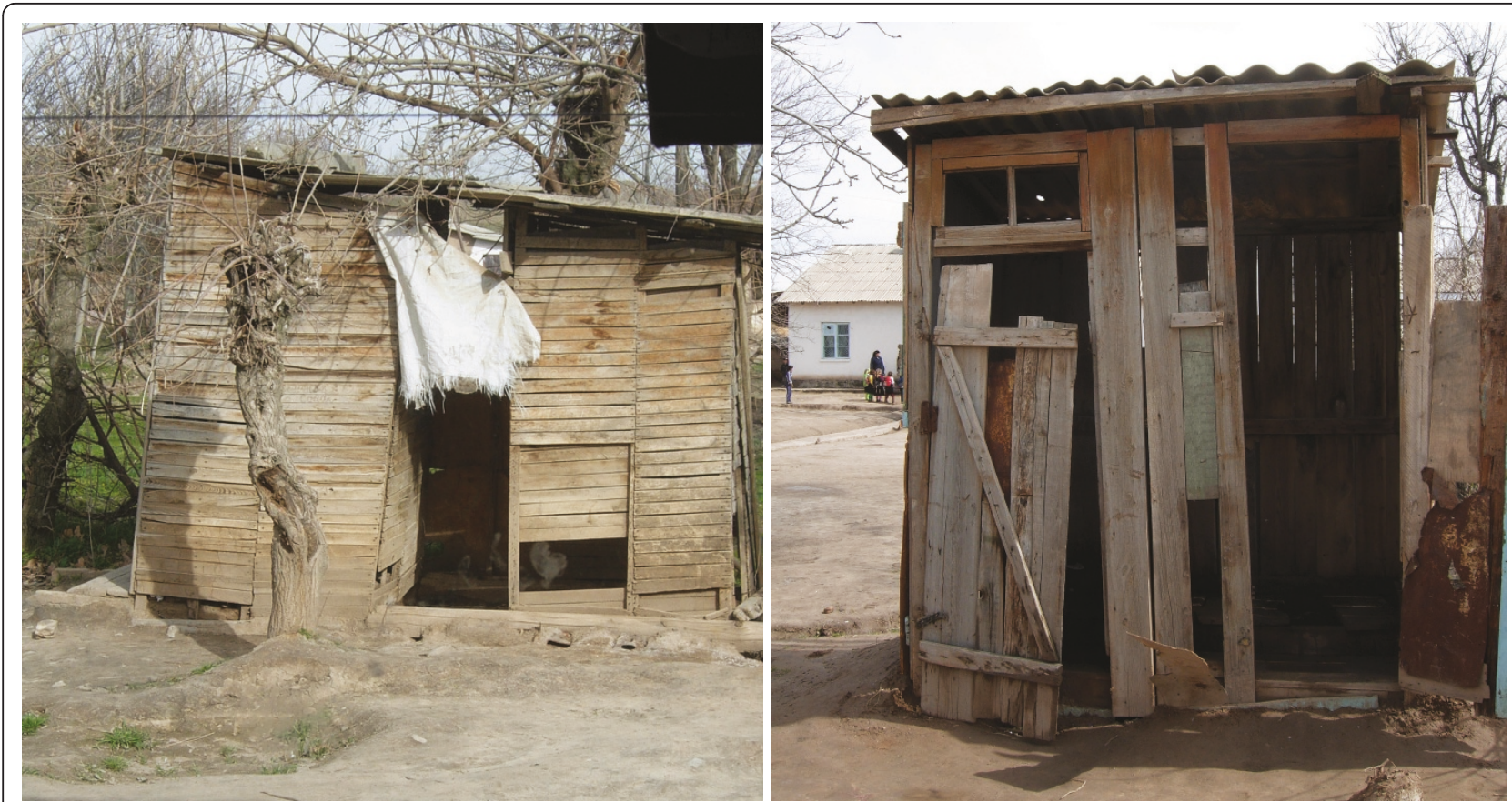

Figure 2 School latrines in two primary schools in western Tajikistan, early 2009.

Unmet drinking water and sanitation standards in Tajikistan partially result from weak services of water supply and public sanitation. Only $23 \%$ of the population had access to a sewage system in 2003; $89 \%$ in urban areas but only $11 \%$ in rural areas [6]. Thus far, active participation mechanisms in water management involving public and private sectors and local communities are poorly developed $[6,43]$.

Interestingly, the use of unimproved drinking water sources did not emerge as a risk factor for G. intestinalis and E. histolytica/E. dispar infection in our study. In other settings, however, water sources were identified as a risk factor for Giardia, as this intestinal protozoon species is commonly transmitted by ingesting cysts persisting in contaminated water or from person-to-person through the faecal-oral route [4]. Our study indicates that the use of drinking water from improved sources (public well/standpipe) is a protective factor for infections with $E$. histolytica/E. dispar, G. intestinalis and $H$. nana. Similar findings were observed for $H$. nana from Kyrgyzstan [7]. The use of tap water was reported to be associated with low infection prevalence of G. intestinalis compared to the use of surface water in a schoolbased survey in Côte d'Ivoire [44]. A study from Mexico City identified the storing of drinking water in unprotected containers (cisterns, tanks and bucks) as a risk factor for G. intestinalis [45].

Our study has some limitations. First, only one stool sample was collected from each participant. Previous research has shown that multiple stool sampling enhances the sensitivity of helminths and intestinal protozoa diagnosis $[46,47]$. Second, the Kato-Katz technique is inappropriate for accurate diagnosis of E. vermicularis and Strongyloides stercoralis. Indeed, the adhesive tape method is recommended for E. vermicularis diagnosis, but there are compliance issues with this method [33]. For $S$. steroralis diagnosis, the Baerman and/or the Koga agar plate method should be used [48]. To partially overcoming these shortcomings, we prepared duplicate Kato-Katz thick smears and preserved 1-2 g of stool that was subjected to an additional diagnostic approach, the ether-concentration method. Data from both methods combined were considered as diagnostic 'gold' standard. Third, no attempt was made to investigate seasonality. We speculate that the prevalence of parasitic infections might be higher in summer when children spend more time outside and might eat more frequently unwashed vegetables and fruits from the garden, as has been observed in neighbouring Kyrgyzstan [49].

\section{Conclusions}

The present study provides new insight into school-aged children's infection status with helminths and intestinal protozoa in ecological 'lowland' areas of western Tajikistan. Considering the high infection prevalence of $H$. nana, E. histolytica/E. dispar and G. intestinalis observed here, a way forward may consist in locally adapted interventions, combining an initial school-based 
deworming and targeted health education programmes, promoting better hygiene and improved sanitation. Treatment with albendazole is proposed to control soiltransmitted helminthiasis, whereas metronidazole should be utilized against the two pathogenic intestinal protozoa. Previous research has shown that carefully designed school-based hygiene programmes effectively contributed to reduce infection intensity and re-infection rates [49-52]. A nationwide deworming programme in Tajikistan is currently conceived by the MoH and the RTDC. In 2010, a total of 32 laboratory technicians received refresher training on specific laboratory diagnostic techniques for identification of soil-transmitted helminths. In our view, further investigations are warranted to assess the true public health burden due to $H$. nana infection to guide future control efforts against this helminth, which represented the predominant species in our study area.

\begin{abstract}
Acknowledgements
We thank all the schoolchildren, parents/guardians, heads of household, teachers, school principals and family doctors for their participation and assistance. We appreciated the support from the heads of jamoats and hukhmats, the Rayon Health Centres and Primary Health Care Network Managers of the health districts of Dangara, Shakhrinav, Tursunzoda and Varzob, and the regional and central management of the Department of State Sanitary Hygiene Surveillance Department. We acknowledge the management of RTDC (Dr. Saiffudin Karimov and Dr. Tohir Sherkanov), Medical Services Department (Dr. Bobokhojaev Oktam Ikramovich), UNICEF Tajikistan (Dr. Bakhruddinov Mutribjon) and the Institute for Zoology and Parasitology (Dr. Zamonidin Karimov) for technical and logistical support. We are grateful to Prof. Giuseppe Cringoli and Prof. Laura Rinaldi (University of Naples 'Federico II', Italy) for providing excellent laboratory facilities for copromicroscopic diagnosis and Dr. Peter Steinmann for scientific input. We thank Dr. Nick Bottone, head of Sino Project and Ms. Dilrabo Jabarova, Mr. Orif Zamirov and Ms. Malika Baimatova for organizational assistance. Our deepest thanks are addressed to the survey team for their commitment. This study was officially authorized by the $\mathrm{MoH}$ and our gratitude is addressed to Dr. Mirzoev Asamjon Safolovich, Deputy MoH. The research received funding by the Project Sino, which is funded through the Swiss Agency for Development and Cooperation (SDC).
\end{abstract}

\section{Author details}

'Swiss Centre for International Health, Swiss Tropical and Public Health Institute, P.O. Box, CH-4002 Basel, Switzerland. 'University of Basel, P.O. Box, CH-4003 Basel, Switzerland. ${ }^{3}$ Republican Tropical Diseases Centre of the Republic of Tajikistan, Str. A. Dehoti 48, 734029 Dushanbe, Tajikistan. ${ }^{4}$ Project Sino, House No 1, $5^{\text {th }}$ drive, Rudaki Avenue, 734001 Dushanbe, Tajikistan. ${ }^{5}$ Department of Epidemiology and Public Health, Swiss Tropical and Public Health Institute, P.O. Box, CH-4002 Basel, Switzerland. ${ }^{6}$ UFR Biosciences, Université de Cocody, 22 PB 770, Abidjan 22, Côte d'Ivoire.

\section{Authors' contributions}

$\mathrm{BM}, \mathrm{JU}$ and $\mathrm{KW}$ conceived and designed the study protocol, data collection forms and questionnaires for interviews. BM and GK planned, coordinated and supervised data collection in the field. GK, ZM and VJR conducted interviews and performed data collection. MB supervised the collection and analysis of parasitological data. MH, MK and LKL provided laboratory analyses of stool samples. Data analysis and writing up of the manuscript was done by BM. BM, JU and KW revised the manuscript. The final version of the manuscript was reviewed and approved by all authors prior to submission.

\section{Competing interests}

The authors declare that they have no competing interests.

Received: 23 June 2011 Accepted: 7 October 2011

Published: 7 October 2011

\section{References}

1. Cairncross S, Bartram J, Cumming O, Brocklehurst C: Hygiene, sanitation, and water: what needs to be done? PLOS Med 2010, 7:e1000365.

2. Hotez PJ, Brindley PJ, Bethony JM, King CH, Pearce EJ, Jacobson J: Helminth infections: the great neglected tropical diseases. J Clin Invest 2008, 118:1311-1321.

3. Bethony J, Brooker S, Albonico M, Geiger SM, Loukas A, Diemert D, Hotez PJ: Soil-transmitted helminth infections: ascariasis, trichuriasis, and hookworm. Lancet 2006, 367:1521-1532.

4. Ali SA, Hill DR: Giardia intestinalis. Curr Opin Infect Dis 2003, 16:453-460.

5. Ali IK, Clark CG, Petri WA Jr: Molecular epidemiology of amebiasis. Infect Genet Evol 2008, 8:698-707.

6. United Nations Development Programme Tajikistan, Republic of Tajikistan: Progress toward the Millennium Development Goals (Tajikistan 2003) Dushanbe: United Nations Development Programme; 2003, 65.

7. Steinmann P, Usubalieva J, Imanalieva C, Minbaeva G, Stefiuk K, Jeandron A, Utzinger J: Rapid appraisal of human intestinal helminth infections among schoolchildren in Osh oblast, Kyrgyzstan. Acta Trop 2010, 116:178-184.

8. PPC Newsletter: How to set up a deworming programme. Action Against Worms Geneva: Partners for Parasite Control (PPC), World Health Organization; 2004, 1: 10.

9. WHO: Preventive chemotherapy in human helminthiasis. Coordinated use of antihelminthic drugs in control interventions. A manual for professionals and programme managers Geneva: World Health Organization; 2006, 63.

10. WHO: Soil-transmitted helminthiasis. Number of children treated 20072008: update on the 2010 global target. Wkly Epidemiol Rec 2010, 85:141-148,

11. Aye R, Wyss K, Abdualimova H, Saidaliev S: Household costs of illness during different phases of tuberculosis treatment in Central Asia: a patient survey in Tajikistan. BMC Public Health 2010, 10:18.

12. Aye $R$, Wyss $K$, Abdualimova H, Saidaliev S: Patient's site of first access to health system influences length of delay for tuberculosis treatment in Tajikistan. BMC Health Serv Res 2010, 10:10.

13. Matthys B, Sherkanov T, Karimov SS, Khabirov Z, Mostowlansky T, Utzinger J, Wyss K: History of malaria control in Tajikistan and rapid malaria appraisal in an agro-ecological setting. Malar J 2008, 7:217.

14. Tediosi F, Aye R, lbodova S, Thompson R, Wyss K: Access to medicines and out of pocket payments for primary care: evidence from family medicine users in rural Tajikistan. BMC Health Serv Res 2008, 8:109.

15. Thierfelder C, Makowiecka K, Vinichenko T, Aye R, Edwards P, Wyss K: Management of pulmonary tuberculosis in Tajikistan: which factors determine hospitalization? Trop Med Int Health 2008, 13:1364-1371.

16. Rebholz CE, Michel AJ, Maselli DA, Saipphudin K, Wyss K: Frequency of malaria and glucose-6-phosphate dehydrogenase deficiency in Tajikistan. Malar J 2006, 5:51.

17. World Population Prospects: The 2008 Population Database. [http://esa. un.org/wpp/unpp/panel_population.htm/, accessed: January 2011.

18. United Nations Population Division: World urbanization prospects: the 2009 revision. New York: United Nations Department of Economic and Social Affairs, Population Division; 2010, 56.

19. The world factbook: Tajikistan. [https://www.cia.gov/library/publications/ the-world-factbook/geos/ti.html], accessed: July 2011

20. United Nations country team Tajikistan: United Nations development assistance framework for Tajikistan 2010-2015 Dushanbe: United Nations; 2009, 80.

21. Gintzburger G, Le Houerou HN, Toderich KN: The steppes of Middle Asia: post-1991 agricultural and rangeland adjustment. Arid Land Res Manag 2005, 19:215-239.

22. WHO: Deworming for health and development. Report of the third global meeting of the Partners for Parasite Control Geneva, Switzerland: WHO; 2005, 64.

23. UNICEF country statistics Tajikistan. [http://www.unicef.org/infobycountry/ Tajikistan_statistics.html], accessed: June 2011. 
24. WHO, UNICEF: Core questions on drinking-water and sanitation for household surveys. Geneva, Switzerland: World Health Organization, United Nations Children's Fund; 2006, 24

25. Katz N, Chaves A, Pellegrino J: A simple device for quantitative stool thick-smear technique in schistosomiasis mansoni. Rev Inst Med Trop Sâo Paulo 1972, 14:397-400

26. Marti HP, Escher E: SAF - Eine alternative Fixierlösung für parasitologische Stuhluntersuchungen. Schweiz Med Wschr 1990 120:1473-1476, (in German).

27. WHO: Bench aids for the diagnosis of intestinal parasitoses. Geneva, World Health Organization; 1994

28. Utzinger J, Botero-Kleiven S, Castelli F, Chiodini PL, Edwards H, Kohler N, Gulletta M, Lebbad M, Manser M, Matthys B, et al: Microscopic diagnosis of sodium acetate-acetic acid-formalin-fixed stool samples for helminths and intestinal protozoa: a comparison among European reference laboratories. Clin Microbiol Infect 2010, 16:267-273.

29. WHO: Prevention and control of schistosomiasis and soil-transmitted helminthiasis: report of a WHO expert committee. WHO Tech Rep Ser 2002, 912:1-57.

30. Filmer D, Pritchett LH: Estimating wealth effects without expenditure data-or tears: an application to educational enrollments in states of India. Demography 2001, 38:115-132.

31. Gwatkin D, Rustein S, Johnson C, Pande R, Wagstaff A: Socioeconomic differences in health, nutrition, and population in Uzbekistan. HNP/ Poverty Thematic Group of the World Bank Washington DC, USA: HNP/ Poverty Thematic Group of the World Bank; 2000.

32. Chero JC, Saito M, Bustos JA, Blanco EM, Gonzalvez G, Garcia HH: Hymenolepis nana infection: symptoms and response to nitazoxanide in field conditions. Trans R Soc Trop Med Hyg 2007, 101:203-205.

33. Jeandron A, Abdyldaieva G, Usubalieva J, Ensink JHJ, Cox J, Matthys B, Rinaldi L, Cringoli G, Utzinger J: Accuracy of the Kato-Katz, adhesive tape and FLOTAC techniques for helminth diagnosis among children in Kyrgyzstan. Acta Trop 2010, 116:185-192.

34. Matthys B: Soil-transmitted helminth infections and intestinal parasitoses in schoolchildren of Kyrgyzstan, Central Asia. UNICEF Kyrgyzstan, Parasitological Unit of the Republican Sanitary Epidemiological Services, Swiss TPH; 2007

35. Gabrielli AF, Ramsan M, Naumann C, Tsogzolmaa D, Bojang B, Khoshal MH, Connolly M, Stothard JR, Montresor A, Savioli L: Soil-transmitted helminths and haemoglobin status among Afghan children in World Food Programme assisted schools. J Helminthol 2005, 79:381-384.

36. Champetier de Ribes G, Fline M, Desormeaux AM, Eyma E, Montagut P, Champagne C, Pierre J, Pape W, Raccurt CP: Helminthoses intestinales en milieu scolaire en Haïti en 2002. Bull Soc Pathol Exot 2005, 98:127-132.

37. Knopp S, Mohammed KA, Khamis IS, Mgeni AF, Stothard JR, Rollinson D, Marti H, Utzinger J: Spatial distribution of soil-transmitted helminths, including Strongyloides stercoralis, among children in Zanzibar. Geospat Health 2008, 3:47-56

38. Rowe WC: "Kitchen gardens" in Tajikistan: the economic and cultural importance of small-scale private property in a post-soviet society. Hum Ecol 2009, 37:691-703.

39. Ellis MK, Raso G, Li YS, Rong Z, Chen HG, McManus DP: Familial aggregation of human susceptibility to co- and multiple helminth infections in a population from the Poyang Lake region, China. Int J Parasitol 2007, 37:1153-1161.

40. de Souza EA, da Silva-Nunes M, dos Santos Malafronte R, Muniz PT, Cardoso MA, Ferreira MU: Prevalence and spatial distribution of intestinal parasitic infections in a rural Amazonian settlement, Acre State, Brazil. Cad Saúde Pública 2007, 23:427-434.

41. Cairncross S, Blumenthal U, Kolsky P, Moraes L, Tayeh A: The public and domestic domains in the transmission of disease. Trop Med Int Health 1996, 1:27-34.

42. WHO, UNICEF: Joint monitoring programme for water supply and sanitation Estimates for the use of improved drinking-water sources. Updated March 2010 Dushanbe; 2010, 7

43. Republic of Tajikistan: Poverty reduction strategy of the Republic of Tajikistan for 2007-2009 Dushanbe: Republic of Tajikistan; 2007, 253.

44. Ouattara M, N'Guessan NA, Yapi A, N'Goran EK: Prevalence and spatial distribution of Entamoeba histolytica/dispar and Giardia lamblia among schoolchildren in Agboville area (Côte d'Ivoire). PLoS Negl Trop Dis 2010, 4:e574.
45. Cifuentes E, Suarez L, Espinosa M, Juarez-Figueroa L, Martinez-Palomo A: Risk of Giardia intestinalis infection in children from an artificially recharged groundwater area in Mexico City. Am J Trop Med Hyg 2004, 71:65-70.

46. Booth M, Vounatsou P, N'Goran EK, Tanner M, Utzinger J: The influence of sampling effort and the performance of the Kato-Katz technique in diagnosing Schistosoma mansoni and hookworm co-infections in rural Côte d'Ivoire. Parasitology 2003, 127:525-531.

47. Knopp S, Mgeni AF, Khamis IS, Steinmann P, Stothard JR, Rollinson D, Marti $H$, Utzinger J: Diagnosis of soil-transmitted helminths in the era of preventive chemotherapy: effect of multiple stool sampling and use of different diagnostic techniques. PLoS Negl Trop Dis 2008, 2:e331.

48. Stothard JR, Pleasant J, Oguttu D, Adriko M, Galimaka R, Ruggiana A, Kazibwe F, Kabatereine NB: Strongyloides stercoralis: a field-based survey of mothers and their preschool children using ELISA, Baermann and Koga plate methods reveals low endemicity in western Uganda. J Helminthol 2008, 82:263-269.

49. Gungoren B, Latipov R, Regallet G, Musabaev E: Effect of hygiene promotion on the risk of reinfection rate of intestinal parasites in children in rural Uzbekistan. Trans R Soc Trop Med Hyg 2007, 101:564-569.

50. Ulukanligil M, Seyrek A: Demographic and parasitic infection status of schoolchildren and sanitary conditions of schools in Sanliurfa, Turkey. BMC Public Health 2003, 3.

51. Hedayati A, Sadraei J, Ghofranipour F: Relationship between the rate of giardiasis and knowledge and practice of prevention in primary school children in south of Tehran. Parasitol Res 2008, 104:169-171.

52. Phommasack B, Saklokham K, Chanthavisouk C, Nakhonesid-Fish V, Strandgaard H, Montresor A, Shuey DA, Ehrenberg J: Coverage and costs of a school deworming programme in 2007 targeting all primary schools in Lao PDR. Trans R Soc Trop Med Hyg 2008, 102:1201-1206.

doi:10.1186/1756-3305-4-195

Cite this article as: Matthys et al.: Prevalence and risk factors of helminths and intestinal protozoa infections among children from primary schools in western Tajikistan. Parasites \& Vectors 2011 4:195.

\section{Submit your next manuscript to BioMed Central and take full advantage of:}

- Convenient online submission

- Thorough peer review

- No space constraints or color figure charges

- Immediate publication on acceptance

- Inclusion in PubMed, CAS, Scopus and Google Scholar

- Research which is freely available for redistribution 